\title{
Using Plastic Bags and Its Damaging Impact on Environment and Agriculture: An Alternative Proposal
}

\author{
Md. Abdul Jalil, Md. Nannu Mian, Muhammad Khalilur Rahman ${ }^{1}$
}

Accepted: June 01, 2013

Published: August 17, 2013

Doi:10.5296/ijld.v3i4.4137

URL: http://dx.doi.org/10.5296/ijld.v3i4.4137

\begin{abstract}
Thousands of plastic factories are producing tons of plastic bags which are very popularly used by the people for shopping purposes because of its ease, cheapness and convenience of use but their very hazardous negative impact is never highlighted or, at the very least, openly discussed in a more serious tone. Many countries have banned plastic bags due to public concern over the serious negative impact on the environment and agriculture, especially, in agricultural countries, such as Bangladesh, India, Pakistan, South Africa, etc. In this research paper, qualitative research methodology has been used to analyze our ideas based on literature review and interview from experts. The paper focuses on the sustainable agricultural and economic development by finding out alternatives to the use of ever harmful plastic bags.
\end{abstract}

Keywords: Plastic bags, environmental degradation, impact on agriculture, non-biodegradable, sustainable development, alternatives to plastic bags.

1. Introduction The global environment is changing day by day and now it has become a challenge to living life forms due to the very ugly fact that every nation is trying to develop their countries without taking into consideration of environmental impact of degradation and pollution of agricultural lands. More and more factories are being steadily established and harmful chemicals and materials are being used in the production process. People are using plastic bags, which are environmentally dangerous products, for their daily needs mainly for shopping purposes as a result of which, the environment and agricultural lands are thereby being polluted. Therefore, in an attempt to reduce the environmental as well as agricultural land pollution, consumers of plastic bags and the business organizations together can play a great role. Over the years, while the business sector has strictly reduced its environmental and agricultural land pollution, such as, waste water and solid waste discharges and energy use, consumers have increased their environmental and agricultural land pollution (such as in the United States) by emitting noxious carbon dioxide gas from industrial sector into the global atmosphere, not to mention the additional problems created by blockage of drains due to water borne discarded plastic bags which have ultimately caused severe flash floods in major urban and suburban areas entailing innumerable financial sufferings. Emission of carbon dioxide has increased by 2 percents from 1990 to 2006, but the emission of poisonous gases in their residential sectors has increased to about 24 percents (US Environmental Protection Agency

\footnotetext{
1 Dr. Md. Abdul Jalil is an Associate Professor, Department of Business Administration, Faculty of Economics and Management, International Islamic University Malaysia. Md. Nannu Mian, an Assistant Professor, Uttara University, Dhaka, Bangladesh and Muhammad Khalilur Rahman is a Master of Marketing student at the Faculty of Economics and Management. The corresponding author's E-mail: abd_jali12@yahoo.com.
} 
[EPA], 2008). However, the negative environmental impacts and agricultural land pollution have been the increased concern of the global community and the caring media around the world.

It is said that people began to use plastic bags to carry groceries and goods by hands or otherwise in the 1970s, (Clapp \& Swantoon, 2009) and these bags became popularized rapidly in the last quarter of the $20^{\text {th }}$ century (Sugii, 2008). No accurate statistics have been seriously made on the total number of plastic bags produced so far, but today about a trillion plastic bags are being nonchalantly used worldwide every year (Miller, R.M., 2012). These bags are very popular with both retailers and consumers, because they are very cheap, strong, lightweight, functional, and as a hygienic means of carrying food and other goods. Although the plastic bags are modern conveniences for carrying goods, they are responsible for the environmental and agricultural land degradation that has incidentally used up precious resources of the earth, in particular, petroleum (Sugii, 2008).

These disposed plastic bags have now found their way to everywhere including the remote areas, like the Pacific Ocean, thus not only posing a threat to aquatic life, but also the landfills and agricultural lands which have now posed a great threat to our environmental and agricultural development as well. The consequent result will be the massive environmental degradation of the world of the so called civilized global community. There had been cases where large turtles of the endangered species had been found to have suffocated due to mistakenly swallowing plastic sheets mixed with seaweeds (Thiel et al, 2003; UNEP, 2005). Only God knows the innumerable number of denizens of the deep that had met similar fate due the plastic sheets that have found their way to the ocean floor. It is very unfortunate that although the plastic bags have been seen to have reduced the agricultural production worldwide, there has been no significant lobbying to undertake a proper, effective and concrete proactive action and no scientific serious investigation has been made by the international organizations and international community to reduce the ever increasing consumption of the plastic bags.

Discarded plastic bags which have also found their way into the ground are not only acutely damaging but also seriously harmful for agriculture. Thus, plastic bags should be banned worldwide and their alternatives which are biodegradable should be introduced in order to resolve these obnoxious and toxic problems. Plastic bag usage may make inroads to cancerous diseases due to the uncontrolled proliferation of carcinogenic substances (Spivey, 2003). Attention to be given to the effect that plastic bags are causing great harm to valuable agricultural lands which is comparable to gold that produces trillions of tons of different types of vegetables and food grains to satisfy our hungry world. Plastic bags are indiscriminately dumped into millions of landfills worldwide which occupy trillions of hectors of lands and emit dangerous methane and carbon dioxide gases during their decomposing stages as well as highly toxic leachates from these landfills (Simons, 2005). It effectively blocks sewerage pipe lines, litters agricultural lands, canals, rivers and oceans. They are not biodegradable as a result of which they contribute very disruptive effects on the agricultural development. They take incredibly long time to break down and when they do, it is into powdery plastic dusts which contaminate all life forms including the soil and the water forever (Stevens, 2001; Michigan Technology University, 2004). On the other hand, plastic bags are made from polyethylene, a product of petroleum, which is a non-renewable natural resource but it is essential for the continuation of modern means of fast transportation and energy generation.

The world community may undertake a test case to ban plastic bags to see its efficacy in reducing environmental and agricultural land pollution. Banning plastic bags might be a good 
example of fostering healthy lifestyles even though involving not so convenient shopping sundry activities. Considering the large scale damaging effect of plastic bags on the agricultural land and the large scale plastic bags production capacity, many countries all over the world have already prohibited the production and use of plastic bags by enacting parliamentary legislations, for instance South Africa, Somalia, Bangladesh, India and some other environmentally concerned countries (Ahmad, 2005; Chauhan, 2003; IRIN 2005; Reynolds, 2002). It is indeed praiseworthy that several European countries have introduced a charge on plastic bags in taking into account of the negative impact of plastic bags on agricultural lands. The Japanese government has also introduced a charge on plastic bags to reduce its production and usage (Funaki, 2007). Prohibition on plastic bags usage and inventing alternatives are the most welcome move than imposing a charge on the production and use of plastic bags by the people; notwithstanding charging a levy on plastic bags obviously has a good impact to protect agricultural lands and to maintain its fertility, but still the subsequent prevalent usage of the plastic bags themselves will defeat the benefits or the advantage on the levy charged.

This research work in fact focuses on the national policy analysis, case studies, environmental degradation and sustainable development issues with regard to the use of random plastic bags for shopping purpose and its eventual riddance into the dust bins. Fresh and healthy environment and increase in agricultural productions are the top priorities at the moment in the contemporary world. This paper proposes a timely legal intervention by the respective governments of different countries to stop the production and the dominant use of plastic bags. It also proposes that the plastic bags which have already been manufactured and are in the hands of people must be collected and burnt to reduce its damaging impact on agricultural growth because of its non-biodegradable and toxic properties and harmful effects. However, we need to encourage the usage of alternatives to plastic bag, such as, jute bags and paper bags etc. which are absolutely biodegradable and sustainable for agricultural development in the world (ELC, 2005; Gray, 2009; Greenfeet, 2004; Hill, 2004).

Australia, Italy, United States of America, Tanzania, Ireland and some other countries have enacted relevant laws to impose tax or to ban the production and use of plastic bags for shopping or other purposes to save the critical environmental conditions the whole world is now facing (AG, 2005; Brown, 2005). Even though the ban on the production of plastic bags will undoubtedly increase agricultural production tremendously, however, some countries are not in favor of implementing the law which prohibits the production and use of plastic bags due to the unscrupulous and unethical pressure indirectly imposed on the respective governments. As a result of which the people are still using these plastic bags to a large extent in those countries because of the dastardly deed of some powerful people (Karliner, 1997). This research investigates the damaging impacts of plastic bags on the environment and agriculture and its consumption pattern implicated therein. The research also looks for developing plastic bag alternatives, such as, jute bags, paper bags, etc., which are convenient for shopping purposes as well as not costly and above all not environmentally damaging. Some of the countries in the world are producing huge amount of jutes, such as, Bangladesh and India in south Asia are able to supply adequate quantity of raw jutes to produce alternative jute bags. Hence, these countries are in a much better position to lobby for the much sought global alternatives of plastic bags.

\section{Objectives of the Article}


The objectives of this article are to analyze the damaging impact of plastic bags on Agriculture based on literature review and secondly to suggest alternative shopping bags which are biodegradable and environment friendly.

\section{The proposed theoretical model}

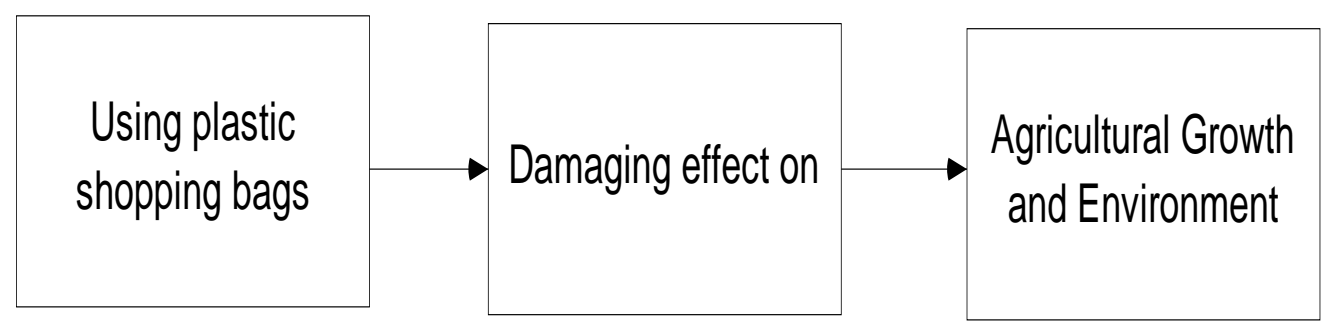

(Source: The authors of this paper)

Hypothesis: Plastic shopping bags cause damages to the growth of agriculture and environment.

\section{Impacts of Plastic Bags on Agriculture}

Plastic bags cause a large scale negative impact on the global agricultural sectors. As people are not conscious to recycle plastic bags, they throw them everywhere as and when they like and as an unavoidable consequence these discarded plastic bags will ultimately find their ways to agricultural fields mixed with other decomposed materials. As plastic bags do not decompose with soil they remain in the agricultural lands and blocks as well retard the progress of growth of agricultural plants. Plastic bags have that inherent property that even though very thin, roots of crops fail to pierce them in order to move around the soil for natural nutrients. Thus, plastic bags have caused tremendous harm to the growth of agricultural produces.

Due to several uncaring factors, around 96 percents of all plastic grocery bags are dumped into landfills (Williamson, 2003). It is well known that plastic bags are non-biodegradable; however plastic bags decompose very slowly, if at all. In fact a bag can last up to 1000 years in the soil inhibiting the breakdown of biodegradable materials around or in it (Stevens, 2001). Plastic grocery bags which are light causes additional harm to the environment as they can be easily blown away by air and as a result they become fixed to tree and plant branches. This makes the environment ugly. These plastic bags also fill ditches of roadsides, rest on public waterways, rivers and oceans. As an example we may refer to the Cape Town of South Africa where there were more than 3000 plastic grocery bags at a certain time that covered each kilometer of road (Ryan and Rice, 1996).

The agricultural impacts of plastic bags are very harmful in several aspects and consequently these bags become the very threat to our food and life. The most common final resting place for the plastic bags is the garbage bin, thus resulting in huge volumes of plastic bags filling the landfills that remain on strategic surfaces of the planet. As the plastic bag is non biodegradable and almost non-compostable (Stevens, 2001), it stays in the soil for an excessively long period of time thereby causing unimaginable harms to the agricultural sectors. The agricultural crops cannot grow where the plastic bags stay because their roots cannot move around due to the ever present of plastic bags. It is really amazing that the thin plastic bags are so strong that the roots 
of trees are unable to pierce it to find its way inside the soil to find nutrients; on the other hand we find plants and trees on the mountains mainly because of the obvious absence of the plastic bags. The most significant negative impacts of the plastic bags on agriculture are: reduction in soil fertility, decrease in nitrogen fixation, huge loss of nutrients in the soil, decrease in crop harvest, disparity in flora and fauna on soil etc. These negative impacts of plastic bags in fact reduce soil fertility to a great extent and thus reduce agricultural production to a great quantity.

\section{Alternatives to Plastic Bags}

There are many environment friendly alternatives to plastic bags, such as, jute bags, paper bags, bio-degradable bags, and reusable bags. Commonly, jute bags are recommended as an environment friendly alternative to plastic bags because the bags are made from biodegradable material which comes from a plant fiber called jute, mostly consisting of cellulose. This is eco-friendly and has no harmful effects on the environment and agriculture. Paper bags are also recommended as an environment friendly alternative to plastic bags. It has been suggested that the natural fibers of paper and its recyclability creates a positive image of the paper bags (Though, 2007; PBWG, 2002). Biodegradable plastic bags are another alternative to the non-biodegradable plastic bags; however, they are not free from environmental harm as they contain toxic materials. Therefore, the alternatives to plastic bags should be carefully assessed before adoption so that they are soil and environment friendly (Though, 2007).

The best alternatives to plastic shopping bags are fully biodegradable bags which are non-toxic for soil. Moreover, they might be manure for the soil after decomposition. Impulsive usage of plastic bags is very harmful and this habit should be changed (PBWG, 2002 Page 21; Though, 2007). Moreover, impulsive purchases are characteristic to the non-supermarket retail sector, where reusable bags are less common and reduction campaigns have had limited success. With no reusable bag readily obtainable at hand, and no environment friendly alternatives being made available, consumers are thus overwhelmed with the experienced convenience and would thus gladly accept or even request for the plastic bags. Thus, impulsive purchases have a significant role in the reduction or increase of the plastic bags consumption and littering, and alternatives provided by retailers can conclusively form a critical factor to the success of reduction in the plastic bag usage. It is recognized that alternatives to the plastic bags provide an opportunity for retailers to consider the most appropriate bags for grocery usages. Furthermore, it is crucial that the bag proclaimed as an alternative to the plastic bags should be convenient for practical purpose of normal usage and also environment friendly.

We need to use alternatives of plastic bags but we must bear in mind that alternative plastic gags should be less or no harmful for our environment especially the agriculture. Agriculture is basically our life. Agriculture supplies raw materials to the industry as food and non-food materials. Any alternatives to plastic bags suggested must have the characteristics of less harmful effects than the current ones or should have preferably zero environmental impact, otherwise there would be no benefit for the people and agricultural development (ACG, 2006, Page 41). This is a very significant factor to consider as natural alternatives might have the potential for greater detrimental impacts on the environment and agriculture than the traditional plastic bags. The natural fiber alternatives that are currently popular are jute bags, paper bags and biodegradable or bio-plastics, in conjunction with the non-renewable alternatives, such as, heavier plastic bags, woven plastic bags and renewable calico, cloth bags (Though, 2007). While numerous alternatives to plastic bags exist, the currently favored alternatives can be categorized in four main groups, such as, jute, paper, biodegradable and reusable bags. The jute bags consist of many types and are biodegradable and quite 
compostable. Besides, they have no negative effect on the environment and agriculture. The category of biodegradable bags incorporates many classes of natural starch-based plastics, synthetic degradable plastics and blended synthetic with natural plastics, with different environmental impacts from each type. In contrast, paper bag is made with one format, although different grades, colors and thickness and alter the environmental impacts of production and use. Finally, reusable bags can be made from both the renewable and the non-renewable sources, including different types and applications of plastics and cloth. Jute bags can be the best plastic bags alternatives which are environment friendly and easily compostable. Bangladesh can supply half of the jute for making shopping bags to the whole world.

\subsection{Jute bags}

Jute bags are manufactured from jute yarn and are used for packing a wide range of industrial and agricultural goods, such as, grains, oil seeds, salt, sugar and other commodities of suitable configuration. The products have a great demand in the industrial and agricultural sectors for packing and wrapping of manufactured and agricultural products. Jute bags are also suitable for shopping and grocery purposes. Jute bags are biodegradable containers made from plant fiber called jute (Rahman, 2009). They are usually used for storing and holding grocery materials. Heavy duty jute bags or sacks are popular for packaging agricultural commodities. Some pictures of jute bags have been placed in the Appendix.

Even though jute bags are replaced by synthetic materials but some natural environmental processes have taken advantage of the jute's biodegradable nature, whereas synthetics would be unsuitable. Jute shopping bags and carriers are increasingly replacing the plastic non-woven ones as ecology friendly alternatives. Jute bags used in the agro-based products treated with vegetable oils to destroy the harmful effect of hydrocarbons are also called hydrocarbon free bags. Due to their biodegradable nature, jute bag is becoming an ecology friendly alternative (Rahman, 2009).

The major raw material required for jute bag production is jute yarn which is a product of South Asia and specifically a product of India and Bangladesh. Nearly $98 \%$ of the world jute is grown in these two south Asian countries. Nepal is another country of south Asia that grows jute but its production volume is not very significant. Another south Asian country, Pakistan, does not produce jute but processes and manufactures a good quantity of jute goods through import of raw jute fiber mainly from Bangladesh.

\section{Benefits and advantages of jute bags:}

- The raw materials of jute bags coming from the lush green jute plants help protect the environment and maintain ecological balance by providing the much needed oxygen to the atmosphere;

- Jute bags are not only bio-degradable and re-usable, but they are also compostable to turn into plant manure.

- The production process of jute bag is simple and, unlike synthetics, it does not involve the use of toxic chemicals with the attendant undesirable harmful byproducts;

- Jute bags preserve the quality of dry food items like rice and wheat as the bags have the inherent aeration property and are safe for storage purposes. They are stable and do not slide down when stacked. Jute bags are also easy to handle both manually and mechanically (Rahman, 2009). 


\subsection{Paper Bags}

Paper bags have traditionally been presented as the environment friendlier option when compared to plastic bags. Prior to the introduction of jute bags, paper bags were the most commonly used for shopping purposes. The natural fibers of paper, and the renewable resource used has a positive image, as the increase in volume of the paper bags, likely to be sent to the landfill, have now taken over a new role in the recycling options which are firmly established (PBWG, 2002). It has been scientifically proven that paper bags are not harmful to the environment as plastic bags (ACG, 2006; Though, 2007). Leather bags are also biodegradable and they are highly recommended for different types of use. Some leather bags have been placed in the Appendix for your perusal.

Despite these significant statistics, the majority of people still do not consider the process used to make and recycle paper bags are better alternatives to the plastic bags. Scottish research has demonstrated that a levy on plastic bags can result in an increase of paper bag consumption (Though, 2007). Imposing a levy on plastic shopping bags is a policy choice for environmental improvement.

\subsection{Biodegradable Plastic Bags}

Biodegradable plastic bags are being manufactured in plastic industries which are less harmful to the soil and environment. Plastic bags produced which are non-biodegradable or biodegradable both are made of toxic ingredients and harmful to the environment (Matlack, 2001; Miller, 2005). So, alternative biodegradable bags which are not made of plastics are most welcome. Adequate research needs to be conducted on discovering alternatives to plastic bags. Irish government also encouraging consumers to use reusable shopping bags which are appreciable as reusable bags will definitely reduce the usage of plastic bags to a great extent and would save the environment from toxicity (Reusable bags, 2005).

The generation of biodegradable plastics has been considered as an alternative to the toxic producing traditional plastic bags. This provides the same environment friendly positive image of natural fibers and bio-degradability that paper or jute bags possess. On the other hand, the increasing public awareness of climate change issues and environmental impacts on consumption has led to the biodegradable plastic manufacture to respond to the international pressure on environmental politics. Thus the need to stop using the non-biodegradable plastic bags has increased. The public pressures on oil reserves and the plastic war have gone a long way to inculcate the public and encourage the use of biodegradable plastics for sustainable development, hence decreasing the widespread use of traditional plastics whilst simultaneously it also increases the market potential of the new generation of biodegradable plastic products for a much broader global usage (BIOCOM, 2006).

Although biodegradable plastic bags are marketed as an environment friendly option, they may probably cause similar but further environmental problems, such as, soil pollution, contamination of recycling streams, social impacts of increased litter, and reduced environmental function (Though, 2007). Biodegradable plastics are being heralded as safer than the usage of non-biodegradable plastics, nonetheless, there are many types of degradable and biodegradable plastics, and to make the problem more challenging, not all of the biodegradable and compostable alternative plastics are environment friendly. As a matter of fact, the definition of biodegradable is varied and often overlooked by many consumers who 
consider biodegradable plastics are not harmful. Moreover, there are both intentional and unintentionally misleading claims of the concerned product performance that increases the negative consumer experiences and leading to claims of green washing. These misleading claims will have significant impacts on the understanding and use of biodegradable plastics.

The term biodegradable has become a popular word in product marketing, and it does not necessarily mean the ingredients are natural or non-harmful. The term biodegradable means capable of being decomposed by bacteria or other biological means (Collins, 2000). Biodegradable items can also include synthetic plastics or blends of starch-based synthetic plastics that can be broken down, degraded or putrefied by biological processes. It does not necessarily mean that all the products or byproducts of this degradation can be easily absorbed into the natural process of environmental cycles. Plastics degraded by biological agents can still leave undesirable synthetic materials in small forms, such as, particles of polymers in the environment where the degradation has occurred, just as traditional polyethylene plastic bags leave when they erode as litter in the environment. Degradable plastic products differ between different types of biodegradable plastics (Though, 2007). So, we need to remember that degradable plastics or traditional polyethylene products are still harmful for agricultural crops and other plants when they decompose into the soil whereas the biodegradable plastics are not.

\subsection{Reusable Bags}

There are many different types of reusable alternatives to plastic bags, such as rigid plastic boxes and baskets; thick plastic bags; woven plastic bags; cloth bags; and the oldest market containers, cane woven baskets (Though, 2007). The use of these alternatives depends on a range of factors, such as, socio-economic status, country, age, price, availability and other numerous social and cultural factors. But one thing must be kept in mind as said above that reusable plastic bags still can cause a lot of environmental toxicity, especially to the agricultural sectors and that their users must be environmental conscious coupled with a sense of civic mindedness. Therefore, the best idea is still to use biodegradable shopping bags and the best biodegradable shopping bags can be made of jutes which can be cheaper and a few Asian countries can supply jute shopping bags world wide as mentioned above.

\section{Data Collection and Analysis}

Data has been collected from 10(ten) interviewees in the relevant field by asking questions from the questionnaires. Majority of the interviewees have given similar opinion while answering the questions. The summary of the questions are as follows:

\section{Question No. 1: Do you think that plastic bags (for shopping) are dangerous for agriculture, why and how?}

Answer summary: Plastic shopping bags are dangerous because they are made of toxic materials. They are non-biodegradable; so they do not rot and mix with soil. As a result the crops and vegetable plants' roots cannot pierce the thin plastic bags in the agricultural lands and cannot grow. Even if they break into dust after a few decades, they produce toxic materials in the soil which makes the agricultural land unfertile and dangerous for crops.

Question No. 2: What is your suggestion to protect the agriculture from the damaging impact of shopping plastic bags? 
Answer summary: The shopping plastic bags should be collected and recycled to protect the agricultural soil. Some say there should have proper disposable method so that plastic shopping bags do not make its way to the agricultural land. Some say biodegradable plastic bags can be produced to reduce the damaging impact of shopping plastic bags.

\section{Question No. 3: Do you think that banning plastic bags would solve the problem? Please elaborate your opinion.}

Answer summary: Majority interviewees say that banning plastic bags and using biodegradable non-toxic shopping bags can save our agriculture. Some say, they do not think that it is practical to ban plastic bags. They think that we can still use plastic bags by making people aware of better disposable method.

\section{Question No. 4: Do you think that imposing plastic tax would solve the problem? Please elaborate your opinion.}

Answer summary: Some says plastic tax can effectively reduce the use of plastic shopping bags as the price of plastic bags will increase. On the other hand it would increase government income. Some others say, the customers should not be given free plastic bags, they have to buy them with higher price from the shopping malls. As a result, the customers will store plastic bags for reuse during next buying. Some say, it is injustice to impose tax on plastic shopping bags as laymen are not aware that plastic bags are dangerous or harmful for agriculture and environment.

\section{Question No. 5: In your opinion what would be the suitable and bio-degradable alternatives to plastic bags?}

Answer summary: Some says biodegradable alternatives to plastic bags would be the best solution to protect our soil fertility and increase agricultural growth. Most of the interviewees say paper bags and jute bags would be the most suitable alternatives to the plastic bags as they are easily biodegradable, non toxic and not expensive.

\section{Conclusion and Suggestions}

Plastic bag is causing irreparable damage to the environment especially to the agriculture all over the world. The environment including its soil, water and air is seriously affected by the use of plastic bags. Plastic bags are manufactured with fossil fuel which emits toxic gas which has become detrimental to the various life forms in the planet (Institute for Lifecycle Environmental Assessment, 1990; Lajeunesse, 2004). Inconsiderate disposal of plastic bags after use and lack of proper management in non-industrial countries are also causing trouble to the environment. Whimsical disposal of plastic bags clog drain pipes, thus contributing to massive floods which have already cost thousands of lives and billions of dollars lost just to repair the damage and restore the public infrastructural facilities (Lane, 2003; McKinney et al, 2003; Plastic bags around the world, 2008). Plastic bags are also problematical to the livelihoods of local people and national governments, both in terms of the loss of agricultural potentials and negative impacts on the tourism industry, in addition to the high cost of cleaning up process which falls on the local and national governments (Ellis et al, 2005).

In May 2011, Debatewise.org carried out online survey whether the plastic bags should be banned; $60 \%$ respondents out of total 500 respondents replied that plastic bags should be banned because plastic bags cause environmental disaster. $40 \%$ of the respondents replied that 
plastic bags should not be banned; instead tax should be imposed on plastic bags. They also argued that banning plastic bags causes loss of jobs; on the other hands people can recycle plastic bags to reduce environmental disaster (Debatewise.org, 2011). It was reported by guardian.co.uk that 13 billion plastic bags are given away by British retailers each year causing serious environmental pollution and damages (debatewise.co.uk, 2007).

Malaysian manufacturing sector has been very vibrant and dynamic in producing plastic products including plastic bags. Malaysia has become one of the largest plastic bag producers in Asia. Plastic bags are being extensively used in every place in Malaysia, such as, supermarkets, small grocery shops, restaurants not to mention the incalculable roadside stalls (Plastic bag reduction around the world, 2009; Porter, 2000). According to Malaysian Plastics Manufacturers Association (MPMA), there has been 30 per cent increased in sale of plain plastic bags and garbage plastic bags which is causing environmental degradation. Malaysian people and politicians want plastic bags should not be given free; charge should be imposed on plastic bags (Boo, 2010; Edwards, 2000).

The situation has been severely aggravated by the whimsical throwing of used plastic bags on the streets and open public places resulting in the unavoidable environmental pollutions. Sometimes plastic bags are burnt emitting toxic smoke that is very harmful to health beside being responsible for creating the green house effect due to the ozone layer depletion, hence, directly increasing the temperature of the global atmosphere. Recent statistics have shown that the temperature in Malaysia is increasing at a slow but steady rate day by day, and the sea water level is rising, the consequence of which may ultimately cause serious alarm to Malaysians on the most likely occurrence of flash floods which recently has been quite frequent. Because of dangerous effect of plastic bags to agriculture and environment Singapore, the neighboring country of Malaysia has already banned plastic shopping bags. Therefore, according facebook.com report 1 (one) million Malaysians want the government to ban plastic bags in Malaysia following Singapore and other countries in Asia and Europe (Plastic bags Malaysia, 2011; OECD, 2004). The Malaysian government should impose a high levy on the plastic bags or better can ban it as soon as practicable and urge the people to use environment friendly biodegradable bags as suggested in this research for sustainable development of environment and agriculture (George Town Penang, 2011).

There are some possible solutions to the problem of the Malaysian plastic bag consumption. Some examples are:

1. Imposing a high levy on all plastic shopping bags supplied by supermarkets and retail stores, following the Irish model or ban it totally as soon as possible (Though, 2007; DEHLG, 2004; Collins, 2002).

2. The Malaysian Government should impose a strict law on manufacturers, importers and the public to recycle plastic bags.

3. Promoting environment friendly sustainable alternatives to plastic bags such as jute bags, paper bags etc (Oriental Overseas Exports, 2010).

4. Introducing legislation requiring the food packaging industry to use biodegradable and compostable materials for packaging purpose. 
5. Government as well as non-governmental organizations should arrange national and international conferences to highlight and seek solutions to the negative impacts of plastic bags and can also announce through radio, television and print media on the short term and the long term harmful effects of plastic bags. The Malaysian government can also encourage people to use environment friendly bags which are not detrimental to the agriculture and the environment.

\section{References}

ACG. (2006). Allen Consulting Group (Ireland).

Ahmed, S. U. (2005). Impact of banning polythene bags on floods of Dhaka City by applying CVM and remote sensing. Environmental Health Perspectives. Vol.111(4), 1471-1474.

Australian Government, Department of the Environment and Heritage. (2005). Action Being Taken on the Plastic Bag Problem. [Online] Available: http://www.deh.gov.au/ settlements/waste/plasticbags/action.html

Baker, R. (2002). Ministerial Brief: Plastic Bag Levy. [Online] Available: http://sres. anu.edu.au/people/richard_baker/examples/briefing/minty/Minty.html

BIOCOM (2006). Naft Asia Biodegradable Plastics Corporation and JSP, Jia Shing Plastic Industries Pte. Ltd.

Boo Su-Lyn, (2011). Penang Questions Plastic Makers' Criticism of Plastic Bag Policy. Online: www.themalaysian insider.com

Brown, S.(2003). Seven Billion Bags a Year. Habitat Australia 31(5) (Oct.): 28

Chauhan, B. (2003). India State Outlaws Plastic Bags. BBC News August 7. [Online] Available: http://news.bbc.co.uk/2/hi/south_asia/3132387.stm

Clapp, J. \& Swantoon, L. (2009). Environmental Policies. Vol.18, No. 3, May 2009, P. 317, Centre for International Governance Innovation, Waterloo, Canada.

Collins. (2002). English Dictionary and Thesaurus also known as primary biodegradation, ultimate biodegradation is the mineralization or incorporation of materials in biomass.

Debatewise.org, (2011). Should Plastic Bags be Banned? Available online: debatewise.org/debates/1011-should-plastic-bags-be-banned; accessed to the internet on 06.09.2011.

DEHLG. (2004). Department for Environment, Heritage and Local Government (Ireland).

DEHLG. (2007). Department for Environment, Heritage and Local Government (Ireland).

Edwards, R. (2000). Bags of Rubbish. The Ecologist 30(8) (Nov. 22). [Online] Available: http://www.theecologist.co.uk/archive_article.html?article=163\&category=76

Ellis, S; Kantner, S; Saab, A; Watson, M. (2005), Plastic Grocery Bags: The Ecological Footprint. 
Environmental Literacy Council. (2005). Paper or Plastic? [Online] Available: http://www. enviroliteracy.org/article.php/1268.html

Funaki, K. (2007). Environmental economic policy for plastic bags. Tokyo, Recycle Bunkasha. George Town Penang. (2011). Plastic Bag Ban Comes into Effect. $2^{\text {nd }}$ January, 2011. Online: www.igeorgetownpenang.com

Gray, L. (2009. Plastic bag use falls by 26 per cent in two years, viewed 14 of September 2010. [Online] Available: http://www.telegraph.co.uk/earth/earthnews/4807924/Plastic-bag-use-falls-by-26-per-cent-intwo-years.html

Greenfeet. (2004). Paper vs. Plastic - The Shopping Bag Debate. Online Available.

Guardian. (2007). Plastic Bags Pollution. Available online: http://www.guardian.co.uk/ environment/2007/nov/13/plasticbags.pollution

Hill, M. K. (2004). Understanding Environmental Pollution: A Primer. Cambridge, UK: Cambridge University Press.

Institute for Lifecycle Environmental Assessment. (1990). Paper vs. Plastic Bags. [Online] Available: http://www.ilea.org/lcas/franklin1990.html

IRIN. (2005a). Kenya: Researchers Recommend Ban on Use of Thin Plastic Bags. IRIN News (UN Office for the Coordination of Humanitarian Affairs) Feb. 24, 2005. [Online] Available: http://www.irinnews.org/report.asp?ReportID=45764\&SelectRegion=East_Africa

IRIN. (2005b). Somalia: Somaliland Bans Use of Plastic Bags. IRIN News (UN Office for the Coordination of Humanitarian Affairs) Mar. 1, 2005. Online Available: http://www.irinnews.org/report.asp?ReportID=45842\&SelectRegion=Horn_of_Africa

Karliner, J. (1997). Corporate Planet: Ecology and Politics in Age of Globalization. San Francisco, CA: University of California Press.

Lajeunesse, S. (2004). Plastic Bags. Chemical and Engineering News 82(38): 51.

Lane, Megan. (2003). Why Can't We Recycle All This Plastic? BBC News September 19. [Online] Available: http://news.bbc.co.uk/1/hi/magazine/3116318.stm

Matlack, A. (2001). Introduction to Green Chemistry. New York, NY: Marcel Dekker.

McKinney, M. L., and R. N. Schoch. (2003). Environmental Science: Systems and Solutions. Mississauga, on: Jones and Bartlett Publishers.

Michigan Technological University. (2004). Life Cycle Analysis of a Plastic Bag. [Online] Available: http://techalive.mtu.edu/meec/module14/Conclusions.htm 
Miller, R.M. (2012). Plastic shopping bags: An analysis of policy instruments for plastic bag reduction'. /thesis submitted to the Universiteit Utrecht for the degree of Msc in Sustainable Development, 2012.

Miller,G. T. (2005). Sustaining the Earth: An Integrated Approach. Pacific Grove, CA: Thomson Brooks/Cole.

OECD (2004). Organization of Economic Development (Ireland).

Oriental Overseas Exports. "Jute and Leather Products in Oriental Stores". See web site: http://www.orientaloverseasexports.com/CommonPages/index.aspx, Accessed to the web site on 10.12.2010.

PBWG (2000); PBWG, (2002) Plastic Bag Working Group (Australia).

Planet Ark. (2005). Why Are Plastic Bags a Problem? Online Available: http://www.planetark. org/campaignspage.cfm/newsid/52/newsDate/7/story.htm

Plastic bag bans around the world (2008). [Online] Available: http://news.bbc.co. uk/2/hi/in_depth/7268960.stm

Plastic bag reduction around the world. (2009). Online Available: http://planet.earthclinic. com/initiatives/plastic-bags.html

Plastic bags Malaysia. (2011). We are 1 Million Malaysians that Support the Ban of Plastic Bags. Online: www.facebook.com/group.php?=17218079609.

Porter, R. C. (2000). The Economics of Waste. Washington, D.C.: RFF Press.

Rahman. R. AKM. (2009). Proceedings of the Symposium on National Fibers (19-20), Jute in South Asia. Online Available: www.jute.org

Reusable Bags. (2005). Facts and figures regarding the true cost of plastic bags. [Online] Available: http://www.reusablebags.com/facts.php

Reynolds, T. (2002). South Africa Moves to Curb Flimsy Plastic Bag Scourge. [Online] Available:

http://www.planetark.com.au/dailynewsstory.cfm?newsid=17971\&newsdate=01-Oct-2002

Ryan, P. G. and N. Rice. (1996). The Free Shopping Bag Debate: Costs and Attitudes. South African Journal of Science 92(4) (Apr.): 163-64.

Simmons, C. (2005). It's in the Bag: An Estimate of the Effect of CO2 Emissions of the Irish

Plastic Bag Tax. [Online] Available: http://www.bestfootforward.com

Spivey, A. (2003). Plastic Bags - Prolific Problems. Environmental Health Perspectives 111(4) (Apr.): A208.

Stevens, E. (2001). Green Plastics: An Introduction to the New Science of Biodegradable Plastics. Princeton, NJ: Princeton University Press. 
Sugii, T. (2008). Plastic Bag Reduction: Policies to Reduce Environmental Impact.

Thiel, M., I. Hinojosa, N. Vásquez, and E. Macaya. (2003). Floating Marin Debris in Coastal Waters of the SE-Pacific (Chile). Marine Pollution Bulletin 46: 224-231.

Though, R. (2007). Plastic Shopping Bags: Environmental Impacts and Policy Options; Victoria University of Wellington.

U. S. Environmental Protection Agency. (2005). Management of Scrap Tires. [ Online] Available:ww.epa.gov/epaoswer/non-hw/muncpl/tires/basic.htm

United Nation Environmental Program (UNEP). (2005). Marine litter: an analytical overview. http://www.unep.org/regionalseas/marinelitter/publications/docs/anl_oview.pdf US Environmental Protection Agency [EPA], 2008.

Williamson, L.J. (2003). It's Not My Bag, Baby! On Earth: Environmental Politics People 25(2) (June): 32-34.

\section{Appendix}

Jute and Leather Products in Oriental Stores
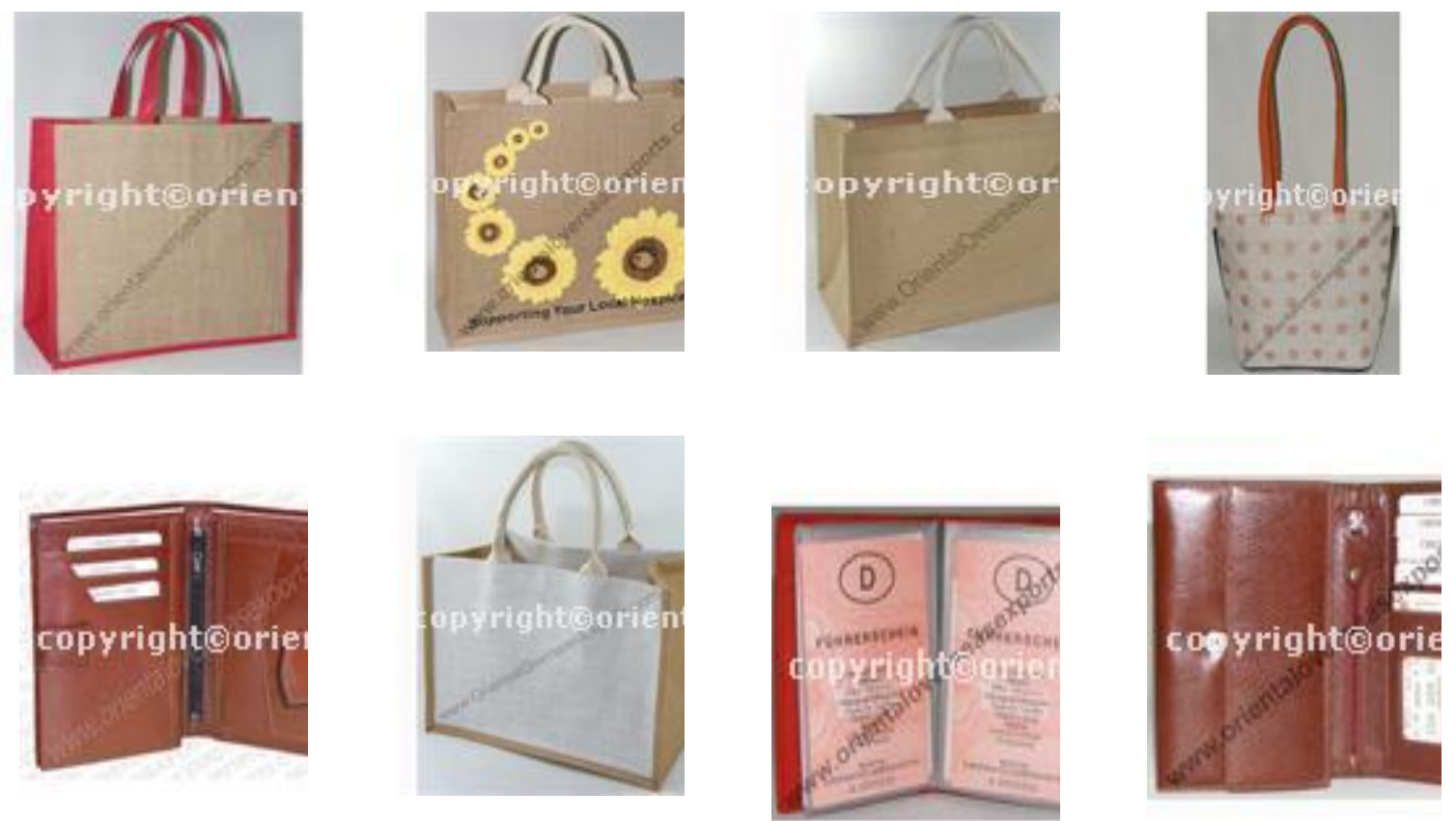